\title{
El erotismo entra en materia citadina
}

\author{
Eroticism: a city issue
}

\section{Dairo Elías González Quiroz}

En la ciudad, nuestra adolescencia "turbaba los cuerpos y deformaba las ideologías, las teologías... En fin, hablar de amor sería, quizá, una simple condensación del lenguaje, después de todo, no provoca en el destinatario más que sus capacidades metafóricas: Todo un diluvio imaginario incontrolable, inexpresable, cuya llave solo posee el amado, aunque no lo sepa..."

Kristeva, 2006: 3

Cabe entonces preguntarnos, será que todo con erotismo y lenguaje le devolveremos los cuerpos a los espacios y paisajes de la ciudad. $\mathrm{O}$, lo que es lo mismo: Será que únicamente con el placer de la carne y la comunicación recuperemos la ciudad para los cuerpos.

Parodiando a Claudia Zavaleta, 2006.

\section{Resumen}

Estos pensamientos sirven de umbral para desear aportar al debate del Seminario de Actualización Docente sobre las Pedagogías Urbanas desde la Escuela, promovido por la Universidad Distrital Francisco José de Caldas en 2007. Por eso, someto a discusión tres imaginarios globales dominantes que he logrado aislar para examinar sus conexiones de época que tocan la producción humanística actual: la ciudad, el lenguaje y la pedagogía.

En consecuencia, el orden de este ensayo es: primero, la introducción que ubica el por qué del mismo y su propósito; segundo, los antecedentes, en que explico el origen de mi proyecto de investigación; tercero, la justificación que plantea la razón de ser del mismo; cuarto, el objetivo general y los específicos de mi trabajo investigativo; quinto: el marco teórico en que ubico los conceptos y autores utilizados; sexto: las actividades, las estrategias y metodologías utilizadas; y séptimo: las conclusiones parciales a las que he llegado.

En otras palabras, este texto tiene como objetivo motivar la reflexión para comprender las relaciones del cuerpo y la ciudad con el lenguaje y la pedagogía, cuestión central en un seminario sobre escuela y ciudad.

Palabras claves: Erotismo, cuerpo, ciudad, lenguaje, educación sexual, literatura erótica y pedagogía crítica y popular.

\section{Abstract}

These thoughts are a first contribution to the debate sustained at the Seminar on Teaching Upgrading on Urban Pedagogical Practices from School, sponsored by the Universidad Distrital Francisco José de Caldas in 2007. For this reason, I will submit to discussion three global dominating imaginaries I have managed to isolate, in order to study their time connections which attain current humanistic production. They are: city, language and pedagogy.

This text starts with an introduction, stating its reason and purpose. Then, there is a background where the origin of the research project is stated. Next, it is presented its rationale. After that, you can read the general and specific objectives of the research. Then, the theoretical framework, followed by the activities, strategies and methods used, and finally, the partial conclusions reached so far.

In other words, this text attempts to promote the reflection to understand the relationship between both body and city, on the one hand, and language and the pedagogy, on the other, crucial issues in a seminar on school and city.

Key words: $\quad$ Eroticism, body, city, language, sexual education, erotic literature, critical pedagogy, and popular pedagogy.

Fecha de recepción: 07 de septiembre de 2007

Fecha de aceptación: 08 de noviembre de 2007

\footnotetext{
Escritor, jefe del Área de humanística y profesor de español y literatura en la Institución Educativa Distrital José Asunción Silva y profesor de talleres de lenguajes y confrontación del PCLEF-2000 de la Universidad Pedagógica Nacional. dgonzalez@pedagogica.edu.co
} 


\section{Antecedentes}

Desde hace años, como educador y padre me vienen preocupando los nuevos "hábitos sexuales de los colombianos", investigados por varios medios, pero sobre todo por la revista Semana (1995: 60), y que los adolescentes se inicien en el sexo cada vez a más temprana edad. Tengo cuatro hijos: dos hombres de 16 y 18 años y dos mujeres de 10 y 20 años. El sinnúmero de discípulos que he tenido y tengo en mi labor docente oscila entre esas edades. Además de poseer un interés personal y profesional por la dimensión de la sexualidad, tengo una visión de ella como parte integral del ser humano.

Por eso, en 1995 escribí "Literatura erótica por la paz", una ponencia que presenté en la VIII Feria Internacional del Libro en Bogotá, cuyo tema central fue Amor y literatura. Ella recoge una experiencia con ex guerrilleros en el Programa para la Paz y la Reconciliación de la Universidad Pedagógica Nacional: he aquí otro antecedente importante de mi actual propuesta. También asistí y participé en el Seminario Cátedra de Literatura y Erotismo en la Universidad del Rosario de Bogotá, Facultad de Educación, del 3 de agosto al 9 de noviembre de 1998. Es obvio, pues, mi interés personal y profesional por la literatura erótica.

Esta propuesta, viene siendo trabajada desde 1999 en el Colegio Distrital José Asunción Silva. En hora buena mi ejercicio profesional me trajo a participar en este seminario de actualización docente porque me permite la oportunidad única de sistematizar dicha experiencia.

\section{Justificación}

El desarrollo de la investigación social, los avances de las tecnologías y la dinámica de los estudios humanísticos han demostrado el predominio y la importancia del lenguaje, el cuerpo, la ciudad y la pedagogía como el fundamento explicativo de todas las cosas que constituyen y revelan nuestro mundo. Por tanto, cualquier análisis de este será incompleto si no se aborda de manera prioritaria el conocimiento de estos, ya que atraviesan diversos ámbitos de la humanidad, la cultura y la sociedad y con mucha más razón el conocimiento y la educación que se imparten en el colegio de un espacio urbano específico. Es lógico pensar, que en un seminario como este no se pueda prescindir del tema Erotismo y Ciudad, el que ha de posibilitar los constructos fundamentales para comprender las relaciones del cuerpo y la ciudad con el lenguaje y la pedagogía, asunto clave en una tendencia curricular integrada que pretende redimensionar su concepción disciplinar en el ámbito de la educación.

En promedio, según una encuesta de Profamilia (Gómez, 1999: 1D), los jóvenes bogotanos tienen su primera relación sexual a los 13 años. Con ello ha crecido el riesgo de enfermedades y embarazos indeseados, lo cual conduce a que alumnas y alumnos se conviertan prematuramente en madres y padres por falta de un mínimo de información sexual en los hogares y en las instituciones educativas, no obstante que desde 1994 los estudiantes de primaria y bachillerato deben recibir la clase de educación sexual (MEN, 1993). Este planteamiento constituye la hipótesis de esta investigación. ¿Qué hacer desde el aula en la clase de lengua castellana para mejorar la responsabilidad en el manejo de la sexualidad juvenil?, ¿qué factores influyen en la juventud de nuestra comunidad educativa para que las niñas salgan embarazadas y los niños se conviertan en padres?, ¿cómo contribuir a que los adolescentes acaben o disminuyan su irresponsabilidad en el manejo de la sexualidad? Es necesario resolver estas preocupaciones pedagógicas porque con ello se contribuye a inculcar en los estudiantes un alto sentido de responsabilidad frente a su cuerpo, a sus relaciones heterosexuales y a la vida citadina, máxime cuando el lema del PEI de nuestra institución es: “Hoy, mujeres y hombres nuevos para el mañana en comunicación y vivencia de valores para una sociedad moderna”. Este "pretende mejorar la calidad de vida formando personas..." (IED José Asunción Silva, 2003: 14).

Lo anterior explica porque mi propuesta se titula: $\mathrm{El}$ erotismo entra en materia citadina, en que la educación sexual y el incremento de la comprensión lectora a través de la literatura erótica se convierte en el eje del área en los grados décimo y undécimo. Así, creemos que nuestro proyecto cumplirá un papel preponderante en este seminario porque toca dos ejes del mismo: erotismo y ciudad, los cuales relacionamos con el quehacer pedagógico de la lengua castellana y la educación sexual de los jóvenes bogotanos.

\section{Objetivos}

\section{General}

Contribuir a inculcar en los estudiantes de los grados décimo y undécimo un alto sentido de responsabilidad frente a su cuerpo, a sus relaciones heterosexuales y a la vida citadina, e incidir en la disminución de los índices de embarazos y enfermedades de transmisión sexual en población joven mediante la lectura y comprensión de la literatura erótica. 


\section{Específicos}

- Mejorar la educación sexual de los jóvenes de educación media vocacional de una institución educativa distrital.

- Incrementar la comprensión lectora a través de la literatura erótica en los grados décimo y undécimo.

- Disminuir el embarazo no deseado de los adolescentes mediante la interpretación lectora que incrementa su responsabilidad frente a su cuerpo y a la vida urbana.

- Despertar una actitud positiva frente a la lectura, para que esta se utilice como instrumento de conocimiento de la realidad citadina a través de las diversas disciplinas.

- Cultivar el gusto por la lectura literaria como medio de mejoramiento social y de desarrollo de una sensibilidad que propicie el disfrute y la creación de las manifestaciones artísticas.

\section{Marco teórico}

Cuanto mayor son las implicaciones de un tema abarcado por una investigación, mayor debe ser la exigencia de una estructura teórica integradora. Dicho sustento conceptual está centrado en Un marco semiótico-discursivo para la docencia del lenguaje y la literatura de Alfonso Cárdenas, en La transformación de la intimidad de Anthony Giddens y en Sexualidades e institución escolar de D. Epstein y R. Jonson, porque ofrecen herramientas interesantes y pertinentes para nuestro trabajo.

Los ejes conceptuales que delimitan nuestro trabajo son el erotismo, la ciudad, el lenguaje y la educación crítica y popular. Considero erotismo todo aquello que parte del fondo del ser, como un estruendo de furia de amor. Esto es, el deseo sexual y algo más. Este algo más es lo que constituye su esencia propia que se nutre de sexualidad. La llama del deseo "es todo aquello que vuelve la carne deseable, la muestra en su esplendor o florecimiento, inspira una impresión de salud, de belleza, de juego placentero..." (Alexandrian, 1991: 8). Woody Allen afirma: "El sexo solo es sucio si se hace bien". Georges Bataille plantea que "el placer corporal es sucio y nefasto: el hombre en estado normal... lo condena o acepta que sea condenado". Sea como sea, el placer de la carne es el valor completo donde se enfrentan el amor y la sexualidad para oponerse o combinarse. Lo erótico se opone a todas las formas de instrumentalidad emocional en las relaciones sexuales. El frenesí corporal es la sexualidad reintegrada en una amplia gama de objetivos emocionales, entre los que la comunicación es lo supremo. El verdadero erotismo sólo es posible cuando cada sexo trata de comprender al otro, logra ponerse en su lugar y hace propias sus fantasías. El camino hacia la cúspide del placer "dignifica el amor y lucha contra la aridez del egoísmo y la incomunicación" (Méndez, 1996: 6). El erotismo es el cultivo del sentimiento, expresado por la sensación corporal, en un contexto de comunicación; un arte de dar y recibir placer" (Giddens, 1995: 182).

El erotismo encierra el proceso

que nace en la mirada, complacida ante la forma y el color del ser humano; en el aroma y las texturas de la piel; se prolonga en las sensaciones táctiles, en la caricia y la calidez de los brazos y se afianza en el beso, para alcanzar su plenitud en el acto sexual.

Lo erótico es "cuanto tiene relación con Eros, el amor, en sus dos acepciones complementarias, lo físico y lo psíquico. En él caben diversas actuaciones y emociones, condicionadas a planteamientos culturales que encaminan al instinto" (Guinard, Jotamario y Chaves, 1990: 23). El arte de dar y recibir placer es la forma de dominación social del instinto, cuyo fin inmediato es la cópula y su consecuencia la perpetuación de la especie; y en este sentido puede equipararse a la técnica. Es el deseo de trascender la lógica de la racionalidad de las necesidades lo que permitirá al hombre encontrarse con el amor. Este rompe con la sexualidad a la vez que la incluye. "El erotismo es la exaltación y aun la sublimación del instinto sexual, no siempre ni necesariamente ligada a la función tenida en el habitual uso de los conceptos y las palabras, por sexual" (Cela, 1982: 15). Entiendo el sensualismo sexual como la capacidad metafórica, como "uno de los elementos más emblemáticos de la vida" (Benetti, 1996: 7) que "rompe con la sexualidad a la vez que la incluye" (Thomas, 1994: 17). Es el espacio curvo en que las relaciones más inesperadas y los encuentros más paradójicos son posibles a cada instante en la búsqueda incesante del placer.

La Ciudad puede entenderse "como el lugar mismo donde da... la urbanización del planeta, en el paso hacia la máquina informática y biológica y el lugar donde se produce la tecnología comunicativa que renueva sensibilidades" (Silva, 2004: 9) culturales y, por supuesto, eróticas. En este contexto, "el cuerpo aparece como el más anhelado objeto de deseo representado tanto en modos de agresión y exclusión como por ser moldeador de lo deseante y liberador" (Ibíd.). Por eso, hoy no podemos vivir sin erotismo y sin lenguajes. Sin ellos la ciudad sólo sería un enorme mercado, vulgar, horrendo y peligroso, sin interés ni alegría, sin señales para nadie. Con erotismo y lenguaje, las ciudades pasan desnudas, con todos los brazos abiertos. 
Este ensayo busca aportar a la configuración del sujeto urbano desde diversas comprensiones de las prácticas pedagógicas y corporales, con el fin de propiciar un espacio en que el erotismo y la ciudad se enfrenten, se cuestionen y se develen, como eternos cómplices, enamorados en su diferencia, en su integralidad y en sus disímiles maneras de expresar y de sentir. Las manifestaciones eróticas urbanas posibilitan cambios en las relaciones y el surgimiento de nuevos mundos. Ellos se enmarcan en la representación que suscita hitos y referentes, propiciando espacios de libertad o represión.

La experiencia humana, lo que para los seres humanos representa la experiencia de la existencia, se realiza desde el lenguaje. El lenguaje representa para los seres humanos, en el decir de Nietzsche, una prisión de la cual no se puede escapar; o, en el decir de Heidegger, la morada de su ser. Los seres humanos habitan en el lenguaje (Echeverría, 1996).

Por eso, entiendo el lenguaje como el escenario de la construcción de la identidad como ámbito del deseo, a partir de los intereses personales estructurados en la lógica de la memoria y entremezclados en el inconsciente, que concretan en el habla acontecimientos significativos que se expresan en la oralidad o la escritura. Pero estas representaciones, en contradicción constante con la sociedad, dependen de ella, "pues la existencia individual no es posible sin el reconocimiento del colectivo" (Navarro, 2004: 14).

A través del uso del lenguaje el hombre vive la realidad. Lo que el sujeto aprende no es pura y simplemente una palabra o expresión, sino un juego de lenguaje completo en que debe utilizar determinadas expresiones lingüísticas en un contexto determinado para obtener ciertos fines. Por esto, el conocimiento y el discurso constituyen uno de los mayores desafíos que deben afrontar las sociedades contemporáneas para su posible desarrollo e incursión en el mundo de la investigación, ayudando a mejorar la actividad humana, permitiéndole entender y comprender la naturaleza.

En este contexto, como jefe del área de humanidades y profesor de español y literatura de mi institución, pienso que

el desafío primordial es hacer posible la comunicación, entendida como una dimensión de la vida que incluye -pero también trasciende- los medios y que, por eso mismo, no puede ser reducida a la existencia de unas tecnologías ni identificadas únicamente con unos procesos de información y de significación... Esta... supone la participación activa dialogal como condición indispensable para no quedarse únicamente en los niveles de la información o de la expresión simbólica (Pérez, 1992: 6).

Pensamos que esta concepción comunicativa sólo es posible encontrarla en la Educación crítica y popular, que concebimos como una Alternativa pedagógica engendrada por la pedagogía popular de Paulo Freire y la pedagogía crítica revolucionaria de Peter McLaren. Sabemos que

La historia de las ideas pedagógicas muestra que la pedagogía, esto es, la teoría de la educación, es hija de las crisis sociales y políticas. Esencialmente, es durante los períodos de crisis social y política que una sociedad se interroga sobre la educación que le da a la juventud... (Charlot, 1979: 22).

Las dos pedagogías citadas son dos grandes ejemplos de lo anterior.

La educación popular y crítica es un tipo de educación que abarca un proceso intencional y organizado mediante el cual se facilita a los diferentes sujetos colectivos e individuales la apropiación, recreación y construcción del conocimiento, las destrezas y los afectos. Esto requiere meterse siempre en los esquemas de significación que los diferentes sujetos tienen. Requiere siempre lo nuevo, nuevas preguntas, problemas, nuevas perspectivas. De este modo, este modelo pedagógico alternativo encierra una práctica sociocultural atravesada por los medios masivos de información y la cultura, influida a la vez por las exigencias económicas, las relaciones sociales y los intereses políticos y cotidianos de las clases dirigentes. Dicho paradigma necesita la fuerza motivadora y productiva de la disputa y la lucha discursiva, al cual debe acceder lo inesperado, lo insospechado, un pensamiento nuevo, una nueva ocurrencia. Así, este tipo de educación se perfila como el saber teóricopráctico generado por los educadores populares y su comunidad a través de la reflexión individual y colectiva sobre la propia práctica a partir de la experiencia y de los aportes de otras prácticas y disciplinas que se encuentran con su quehacer.

La educación popular y crítica será manantial humano en la medida en que se vaya logrando la participación dialógica, en la cual interactúen todos los sujetos, puedan expresarse libre y creativamente, confrontando en forma constructiva opiniones y propuestas. Entiendo al aprendizaje como estrategia de construcción de herramientas para la valoración y recuperación de sentidos y significaciones mediante la puesta en práctica de experiencias transformadoras. Dentro de este humanismo, los educadores populares y críticos escogemos la libertad, la entrega, la honradez y la bondad como prin- 
cipios dadores de sentido y dirección a la existencia. En esa educación está la cultura del cambio y la cultura del respeto a la vida y a la gente. Ella reivindica la libertad, la justicia, la igualdad y la democracia plena; es una alternativa pedagógica que mira diferente a los distintos sujetos que intervienen en el proceso educativo. Solo con ella, los educadores podemos quebrantarle el espinazo a la irresponsabilidad juvenil frente a su cuerpo, a sus relaciones heterosexuales y a la vida citadina que tantos tormentos y vapuleos está causando a las familias de hoy.

\section{Actividades, estrategia y metodología}

El procedimiento metodológico de la educación sexual a través de la literatura erótica ha girado alrededor de los pasos siguientes:

- Entrega de un poema o cuento a cada uno; el profesor lee como un relator cada texto en público, respetando, después de la lectura, las reacciones de los alumnos (silencios, risas o exclamaciones).

- Resolución de algunos interrogantes.

- Discusión participativa y democrática en torno a estos aspectos: ¿te gustó?, ¿por qué?, ¿de qué trata?, ¿qué recuerdos te trajo?, ¿qué opinas del texto?

- Conclusiones referidas al texto y contexto, y compromisos de disfrutar la sexualidad con anticonceptivos.

- Despojándose de todo perjuicio cada uno intenta escribir un texto erótico que comparte con su curso. Cuando se trata de una novela, nuestra estrategia encierra: ubicación textual y contextual de la obra; lectura interpretada del primer capítulo; resolución previa de algunos interrogantes; concertación de la fecha para la realización de la mesa redonda sobre la lectura total de la novela; realización de técnica grupal con una guía previa que busca mayor responsabilidad para no traer más seres humanos en condiciones desfavorables.

Esta estrategia ha permitido responder parcialmente a las preguntas pedagógicas mencionadas; ha posibilitado el alcance de nuestros objetivos (disminuir el embarazo no deseado de los adolescentes, identificación de los factores influyentes de la irresponsabilidad en el manejo de la sexualidad juvenil e incrementar la comprensión lectora de los educandos a través de la literatura erótica), y ha facilitado el proceso integral de la lectura del texto y de la realidad, lo cual supone que la semiótica y la teoría del discurso son instrumentos de análisis eficaces, según Cárdenas (1995: 5), para "las diversas instancias de la semiotización (cultural), de la semantización (texto) y de la comunicación (contexto)". La interacción con el medio "es de vital importancia porque las acciones del profesor dependen del entorno y la actividad docente es una responsabilidad social que apoya el proceso de formación del ciudadano" (Premio Compartir al maestro, 2003: 19). Por eso, el diálogo con Asopadres y la junta comunal ha sido constante y permanente.

Las construcciones conceptuales mencionadas se pusieron a prueba en la práctica de la metodología interactiva, desde las cuales los jóvenes y adolescentes reflexionaron en torno a aspectos como publicidad y cuerpo, erotismo y ciudad, erotismo y pornografía, erotismo y literatura, el goce y el disfrute, el mundo del sentir y la sexualidad. A partir de allí, fueron ellos mismos quienes propusieron otras maneras de entender el tema y surgieron iniciativas que posibilitaron la reflexión y participación en los temas de una sexualidad ligada no solo con la salud, sino relacionada con el mundo de la deliberación y la emancipación de los sujetos, y desde las singularidades expresadas en el mundo del deseo, más que desde los modelos mediáticos y de la globalización.

\section{Conclusiones}

El enfoque propuesto plantea que ser madres o padres adolescentes involucra la poca idoneidad de las fuentes de información a las que acuden los jóvenes (grupos de amigos y mass media) y la debilidad en los canales de comunicación entre la juventud y la sociedad. También

se desconocen las capacidades, conocimientos y saberes que los mismos jóvenes y adolescentes pueden aportarle a la sociedad y a la cultura. Puede ser que esto ocurra por aquella mirada desconfiada que califica socialmente a los jóvenes y adolescentes como incompletos y carentes.

Como bien lo dice un investigador de Observatorio de Juventud de la Universidad Nacional de Colombia (Navarro, 2004: 14). Además, es una metodología que propicia el diálogo entre jóvenes desmitifica el enfoque de peligro con el cual tradicionalmente se ha juzgado su sexualidad, porque facilita la expresión de sus necesidades, sentimientos y sentidos.

Un año después de nuestra propuesta, iniciada en 1999, los problemas sexuales comenzaron a disminuir en los grados décimo y undécimo porque ha habido menos niñas embarazadas y menos niños-padres, lo cual se comprueba a través de diálogos directos con ellos y sus familiares, también a través de la aplicación de encuestas a los mismos y la observación directa de los hechos, registrados en un Cuaderno de observación: 


\begin{tabular}{|ccccc} 
Año & $\begin{array}{c}\text { Niñas- } \\
\text { madres }\end{array}$ & $\begin{array}{c}\text { Disminución } \\
\text { con relación } \\
\text { al año anterior }\end{array}$ & $\begin{array}{c}\text { Niños- } \\
\text { padres }\end{array}$ & $\begin{array}{r}\text { Disminución } \\
\text { con relación } \\
\text { al año anterior }\end{array}$ \\
\hline 1997 & 10 & igual & 5 & igual \\
1998 & 10 & igual & 5 & igual \\
1999 & 10 & $10 \%$ & 4 & $20 \%$ \\
2000 & 9 & $11,22 \%$ & 3 & $25 \%$ \\
2001 & 8 & 12,5 & 2 & $33,33 \%$ \\
2002 & 7 & $14,29 \%$ & 2 & igual \\
2003 & 6 & $16,33 \%$ & 2 & igual \\
2004 & 5 & $16,33 \%$ & 2 & igual \\
2005 & 4 & $16,33 \%$ & 1 & $50 \%$ \\
2006 & 3 & & & \\
\hline
\end{tabular}

Además, los estudiantes de dichos grados han empezado a liberase del miedo a hablar del tema en el aula, y ya no es extraño escuchar versiones sinceras de sus aventuras sexuales, sus fantasías eróticas y sus problemas de cama.

Apoyados en la cultura, el texto y el contexto, los educandos se han sentido orientados clara y objetivamente en lo esencial del erotismo y en las respuestas a sus dudas sobre la anticoncepción; incluso (seducidos) han acariciado el papel virgen o desflorado y han producido, dolorosamente complacidos, sus escritos que han aparecido en Pluma Estudiantil y en El Anuario, publicaciones de nuestro colegio. Es más, las conclusiones parciales de este trabajo han sido comunicadas a colegas de este y otros colegios, en reuniones docentes. Los profesores del área de mi institución han empezado a colaborar con la propuesta leyendo textos eróticos en sus clases, lo cual ha permitido información pertinente y oportuna a estudiantes de cursos inferiores.

La elaboración e implementación de esta propuesta pedagógica ha influido positivamente en mi práctica docente: he mejorado mi relación con los educandos y padres de familia. Incluso, el mejor puntaje de las prue-

110 bas de Estado ha sido el de nuestra área (estadísticas del Icfes lo confirman) un año después de haberse iniciado el proyecto. Este no ha necesitado apoyo o alianzas económicas con ninguna empresa educativa, lo cual se ha convertido en un importante logro profesional e institucional. Además, ha posibilitado mi consolidación académica en el campo de la literatura erótica y una mejor reflexión de nuestra práctica pedagógica.

Es necesario entender que el problema de las niñas embarazadas y los niños padres "está inmerso en un contexto donde se entretejen diversidad de factores, generando una trama compleja, y que, al igual que sucede con otras formas dolorosas de expresarse ante el caos de nuestra sociedad, la juventud está lanzando un grito de alarma" (Lafaurie, 2004: 15). De todas formas, la falta de cuidado, de educación o de adecuada formación es la razón fundamental para ser madre o padre prematuramente. Sin embargo, hay otras razones no tan secundarias: para las adolescentes, la falta de oportunidades es factor importante. "Creen que su única función en la vida es ser mamá. O creen que quedar embarazada es una forma de salir de casa. La violencia en los hogares es muy alta: Una de cada dos mujeres ha sido víctima de violencia física o psicológica en su casa (Plata, 2007: 1-16). Para los chicos, "es una forma de mostrar su virilidad y demostrar a su familia que son hombres, que no son tan irresponsables como les han dicho toda la vida; que los dejen de tratar como niños chiquitos. En las niñas, el tema es la idealización de la maternidad, a la que consideran función vital de la mujer" (Ibíd.). Entonces, la obtención de oportunidades sociales y el ejercicio de una "libertad" sexual en tiempos modernos podrían estar motivando el aumento de jóvenes irresponsables y adolescentes embarazadas.

Es preciso tener en cuenta que el embarazo de las
niñas escolares es, en parte, producto de la cultura
del placer que les ha inculcado donde el sexo es solo
un mecanismo para divertirse; del exhibicionismo
que caracteriza la moda juvenil y las hace atractivas
para abusadores sexuales; del aparato publicitario
que las ha convertido en mercancías deseables ante
todo por sus formas; y de un medio social que las
presiona a ser seductoras para ser aceptadas (Ma-
rulanda, 2001: 2-16).

Sabemos que no hace mucho tiempo, "la mujer debía tener tetas grandes, cadera florentina, labios húmedos. El cine y la TV empujaron esa imagen, y las mujeres y, sobre todo, los hombres, las adoptamos" (Molano, 2004: 16A) con el tema "tetas y colas matan neuronas" porque "sin tetas ni colas no hay paraíso". Pero hoy la imagen ideal es la mujer habichuela: labios henchidos de deseos; calzones de los que casi se desprende el olor; larga y flaca, y voluptuosa solo ahí donde imaginas. Es claro, entonces, que la cultura del placer, el exhibicionismo, la publicidad y la presión del medio social tienen mucho que ver con el embarazo juvenil; pero ante todo, es resultado de un mundo regido por el permisivismo total, que se traduce en irresponsabilidad en todo nivel.

Por todo lo anterior, "es indispensable la educación sexual. Tiene que haber una cátedra formal y obligatoria. Así como nos enseñaron a leer, nos tienen que educar sexualmente. Ese es un derecho de los adolescentes", como bien lo dice la directora de Profamilia, María Isabel Plata (2007: 1-16). 
Entiendo la educación sexual como un proceso formativo integral y sistemático que tiene que ver con la sexualidad; formación sobre toma de decisiones, sobre el ejercicio de los derechos de los adolescentes, sobre qué quieren hacer ellos con la vida y cómo quieren desarrollarla. Conducirlos en su proyecto vital, lo cual se puede hacer desde la cátedra formal y obligatoria de la que habla la señora Plata, y desde todas las áreas porque en la sexualidad está la dimensión universal de ser humano. Indudablemente, es más que una cátedra sobre cómo evitar embarazos o ser padres prematuramente, porque es enseñar a desarrollar proyectos de vida: es aprender a definir los objetivos de la existencia; es enseñar a saber qué quiero hacer, cómo lo quiero hacer; es conocer mi cuerpo y su funcionalidad; qué es la sexualidad, cómo manejo los sentimientos, cómo tengo relaciones con los muchachos, o ellos con las niñas, sin necesidad de actividad sexual; cómo podemos desarrollarnos sin encontrar un embarazo que no queremos; que demoren un poquito el comienzo de la actividad sexual o si lo deciden, que se cuiden para tirar seriedad con la sexualidad.

Este trabajo muestra que existe evidencia de que una educación sexual "basada en teorías y modelos demostrados en las ciencias sociales y humanas, al igual que en salud, es útil para formar adolescentes y jóvenes que tengan una visión de la sexualidad como parte integral del ser humano" (Parada, 2005: 9). Esta perspectiva contribuye a aumentar los conocimientos de los jóvenes respecto al tema, aplazar el inicio de sus relaciones sexuales, disminuir la gestación en las madres y padres adolescentes, a que las parejas que ya tienen relaciones utilicen con mayor frecuencia métodos anticonceptivos, tener una vivencia de la sexualidad con mayor responsabilidad y respeto por las diferencias.

Aunque hay ajustes por hacer, al colegio se le está poniendo a cargar con un peso demasiado grande cuando se reduce el problema de la fecundidad adolescente a fallas en la educación formal en sexualidad. El problema, la construcción consciente y la responsabilidad colectiva de una mirada sobre la sexualidad competen a todas las instancias institucionales y requieren un enfoque integral que contemple los factores económicos, políticos, sociales, biológicos, psíquicos y culturales que inciden en su percepción y construcción y en su simplificación y complejización. La idea es perfeccionar esta investigación para llevarla a foros educativos locales y nacionales, para enriquecerla y armar un libro para proponérselo a alguna editorial especializada que lo publique, con la garantía de una difusión masiva y un seguimiento riguroso porque el asunto no es exclusivo de nuestra ciudad, sino nacional. $4 \mathbb{D}$

\section{Bibliografía}

Alexandrian. (1991). Historia de la literatura erótica. Bogotá: Planeta. Amat, Yamid. (2007, 19 de agosto). 42\% de adolescentes embarazadas ¡querían ese embarazo! Reportaje de Yamid Amat a María Isabel Plata, directora de Profamilia. En El Tiempo, cuadernillo 1, p.16. Bogotá.

Bataille, Georges. (1985). El erotismo. Barcelona: Tusquets.

Benetti, Mario. (1996, junio). El amor, las mujeres y la vida. Poemas de amor. Selección y prólogo del autor. Santafé de Bogotá: Planeta.

Cárdenas, Alfonso. (1995). Un marco semiótico-discursivo para la docencia del lenguaje y la literatura. Mimeografiado. Bogotá: Universidad Pedagógica Nacional, p. 5.

Cela, Camilo José. (1982). Obra completa, tomo 14. Enciclopedia del erotismo 1, Barcelona: Ediciones Destino.

Echeverría, Rafael. (1996). Ontología del lenguaje. Santiago de Chile: Dolmen Estudio.

Foucault, Michael. (2001). La historia de la sexualidad. México: Siglo XXI Editores.

Giddens, Anthony. (1995). La transformación de la intimidad. Sexualidad, amor y erotismo en las sociedades modernas. Madrid: Ediciones Cátedra, 182.

Gómez, Lucevín. (1999, 9 de julio). Sexo un juego precoz. Testimonio de jóvenes. El Tiempo.p. $1 \mathrm{D}$.

Guinard, Fernando Jotamario y Chávez Mendoza, Álvaro. (1990). El espíritu erótico. Bogotá: Taller de-mente Colombiano, p. 23.

Institución Educativa Distrital José Asunción Silva. (2003). Regla- mento o Manual de Convivencia. Bogotá: C \& C Editores, p.14.

Jaime Pérez, Gabriel. (1992). Desafíos de los medios de Comunicación a la familia que se prepara para el tercer milenio. Signo y Pensamiento, 21. Bogotá: Pontificia Universidad Javeriana, Facultad de Comunicación Social.

Kristeva, Julia. (2006). Historias de amor. México: Siglo XXI Editores.

Lafaurie, María Mercedes. (2004). La cara fecunda de la modernidad. Bogotá: UNPeriódico. c. 2, p. 16. .

Ministerio de Educación Nacional. (1993). Proyecto Nacional de Educación Sexual para la vida y el amor. Bogotá: MEN.

Molano Bravo, Alfredo. (2004). Perchas. Bogotá: El Espectador. 1 de septiembre, p.16.

Navarro V., Fernando, (2004). El deseo juvenil tiene voz. Bogotá: UNPeriódico, 22 de agosto, p. 14.

Paz, Octavio (1995). La llama doble. Amor y erotismo. Bogotá: Editorial Presencia.

Revista Premio Compartir al Maestro. (2003). Cinco años. Bogotá: Fundación Compartir, p. 19.

Semana. (1995 18 de abril). Sexo en Colombia. Por primera vez los colombianos confiesan sus hábitos sexuales, n. ${ }^{\circ} 676$, p. 60 . Bogotá.

Silva, Armando (2004). Arte e imaginarios globales. En Lecturas fin de semana de El Tiempo. 13 de noviembre, p. 9. Bogotá.

Thomas, Florence. (1994). Los estragos del amor. Bogotá: Universidad Nacional de Colombia, p. 17.

Zavaleta, Claudia. (2005). El paisaje en la relación cuerpo ciudad. Memorias de Foro sobre urbanismo y paisaje. Vitoria. 